\title{
Vividly coloured poppy flowers due to dense pigmentation and strong scattering in thin petals
}

\author{
Casper J. van der Kooi ${ }^{1}$ (D) Doekele G. Stavenga ${ }^{2}$ D
}

Received: 17 October 2018 / Revised: 19 December 2018 / Accepted: 24 December 2018 / Published online: 28 January 2019

(c) The Author(s) 2019

\begin{abstract}
The flowers of poppies (Papaveraceae) exhibit bright colours, despite their thin and floppy petals. We investigated the optical properties of flowers of Papaver rhoeas, P. dubium, Meconopsis cambrica and Argemone polyanthemos using a combined approach of anatomy, spectrophotometry and optical modelling. The petals of Papaver flowers are composed of only three cell layers, an upper and lower epidermal layer, which are densely filled with pigment, and an unpigmented mesophyll layer. Dense pigmentation together with strong scattering structures, composed of serpentine cell walls and air cavities, cause the striking poppy colours. We discuss how various aspects of the optical signal contribute to the flower's visibility to pollinators.
\end{abstract}

Keywords Papaver $\cdot$ Pollination · Anthocyanin $\cdot$ Bee vision $\cdot$ Reflectance

\section{Introduction}

Flowers have been called sensory billboards (sensu Raguso 2004), because they feature numerous traits to entice pollinators. The bewildering diversity in floral colours is considered to have evolved with respect to the visual perception of their pollinators (e.g., Barth 1991; Chittka and Menzel 1992; Dyer et al. 2012; Muchhala et al. 2014; Shrestha et al. 2016). The colours of flowers are due to two basic optical principles: (1) reflection and scattering of light by the floral structures, and (2) selective absorption in a specific wavelength range by floral pigments (van der Kooi et al. 2016, 2019). Scattering occurs because petals consist of media with different refractive indices, such as cell walls, air cavities, water-filled vacuoles, and thus incident light is reflected and scattered at their interfaces (Kay et al. 1981; Kevan and Backhaus 1998;

Electronic supplementary material The online version of this article (https://doi.org/10.1007/s00359-018-01313-1) contains supplementary material, which is available to authorized users.

Casper J. van der Kooi

c.j.van.der.kooi@rug.nl

1 Groningen Institute for Evolutionary Life Sciences, University of Groningen, 9747 AG Groningen, The Netherlands

2 Computational Physics, Zernike Institute for Advanced Materials, University of Groningen, 9747 AG Groningen, The Netherlands
Lee 2007; Vignolini et al. 2012; van der Kooi et al. 2014). Pigments absorbing in a specific wavelength range filter the light flux travelling inside the petal, giving the flower a certain hue. For example, blue-absorbing carotenoids create yellow colours, and blue-green-absorbing anthocyanins create red colours. Though the chemistry, molecular synthesis and evolution of floral pigments have been extensively studied (e.g., Koes et al. 1994; Mol et al. 1998; Grotewold 2006; Rausher 2008; Hopkins and Rausher 2011; Zhao and Tao 2015; Sheehan et al. 2016), much remains unknown about how light propagates in a flower and how backscattering structures and pigments are tuned.

We recently studied the pigmentation and scattering properties of 39 species of flower, and found that flowers of the common poppy, Papaver rhoeas, are exceptional in various ways. $P$. rhoeas has fairly large and exceedingly thin petals, yet they are deeply coloured and are relatively strong scatterers (van der Kooi et al. 2016). These findings raise the question as to the anatomical details of $P$. rhoeas flowers that cause the extreme optical characteristics, and whether related species share similar properties.

Poppies are a group of genera in the subfamily Papaveroideae of the Papaveraceae, which is an early diverging eudicot family. They include species of Papaver, Meconopsis, and Eschscholtzia, and comprise many iconic species well-known for their showy flowers. Several of these species, such as $P$. rhoeas, $P$. somniferum (opium poppy), Meconopsis grandis (Himalayan poppy) and Eschscholtzia 
californica (California poppy) are popular ornamental and garden plants. For a few species, the characteristics of their flower colours have been studied in some detail. For example, the chemistry and vacuolar $\mathrm{pH}$ have been studied for blue-flowered Meconopsis species (Yoshida et al. 2006). E. californica has been investigated because of its pigmentation via the specific pigment eschscholtzxanthin (e.g., Strain 1938) and because of its ultrastructure (Wilts et al. 2018).

Here, we investigate the flower colours of $P$. rhoeas, $P$. dubium (long-headed poppy), the closely related Meconopsis cambrica (Welsh poppy), which has both yellow and orange colour morphs, and Argemone polyanthemos (crested prickly poppy). Using photography, spectrophotometry, optical modelling, and various anatomical techniques, we show that a high pigment content together with scattering air holes cause the typical coloration of these thin flowers. We discuss our results in context of the plant's ecology and visual ecology of their pollinators.

\section{Materials and methods}

\section{Plant material and photography}

All flower samples were obtained from road sides and meadows around the campus of the University of Groningen, except for flowers of A. polyanthemos, which were grown from seeds purchased at De Bolster, Epe, The Netherlands. Flowers were photographed with a digital camera (Nikon D70) equipped with an F Micro-Nikkor macro objective (60 mm, f2.8, Nikon, Tokyo, Japan). Petal details were photographed with an Olympus DP70 digital camera mounted on an Olympus SZX16 stereomicroscope (Olympus, Tokyo, Japan), or with a Zeiss Universal microscope (Zeiss, Oberkochen, Germany) equipped with a DCM50 camera (Mueller Optronic, Erfurt, Germany).

\section{Spectrophotometry}

Reflectance and transmittance spectra of petals were measured with an integrating sphere (for technical details and measurement procedures, see Stavenga and van der Kooi 2016). The sphere's measurement area (its aperture) is approximately $5 \mathrm{~mm}$. In contrast to the commonly used reflectance probe, an integrating sphere allows measuring the absolute amount of backscattering as well as the modulation of the spectrum (for further discussion on the sphere and probe, see Vukusic and Stavenga 2009). The pigment absorbance spectrum was measured with a microspectrophotometer (MSP, see Stavenga and van der Kooi 2016). A piece of flower was immersed in water; the measurement area was a square with side length $\sim 10 \mu \mathrm{m}$. We subtracted the long-wavelength absorbance, which is due to scattering, to estimate the contribution of the absorbing pigments. Measurements were taken from flowers of at least three individuals per species.

We also investigated the angle dependence of the reflectance by illuminating the flat surface of a $P$. rhoeas petal with a rotatable fibre and collecting the reflected light with another rotatable fibre, positioned at the mirror angle of the illumination. The latter fibre was fitted with a polarizer, which allowed measurement of reflectance spectra as a function of angle of light incidence for both TE (transverse electric) and TM (transverse magnetic) light.

\section{Anatomy}

The thickness of the petals was measured on pieces placed in between two cover slips with a thickness gauge. We measured the thickness for each flower five times on a transect from the proximal to distal part of a petal, for 3-5 individuals per species (Table 1). The pigment distribution of the flowers was examined via transverse sections of flower pieces. Flower pieces were embedded in $6 \%$ agarose solution at a temperature of approximately $55{ }^{\circ} \mathrm{C}$, i.e., close to the temperature of solidification. Transverse sections were cut using a sharp razor blade and immediately examined with the Zeiss Universal microscope. Satisfactory results could be obtained only for M. cambrica. Essentially, the same distribution was observed for the other studied species, but the very thin Papaver petals precluded obtaining presentably clear pictures.

\section{Optical modelling}

We used the measured reflectance and transmittance spectra of the petals to calculate the petals' overall absorption and scattering parameters. A flower can be considered as a stack of layers, where different layers have specific scattering and pigmentation properties (van der Kooi et al. 2016). Light microscopical observations as well as thickness measurements on P. rhoeas and P. dubium flowers suggested that the flowers are composed of only a few cell layers (Table 1). In

Table 1 Thickness measurements (in $\mu \mathrm{m}$ )

\begin{tabular}{llrlll}
\hline Species & $\begin{array}{l}\text { No. } \\
\text { individual } \\
\text { plants }\end{array}$ & Min & Max & Mean & SD \\
\hline Papaver rhoeas & 5 & 56 & 266 & 108 & 62 \\
Papaver dubium & 5 & 48 & 319 & 101 & 65 \\
Meconopsis cambrica yellow & 5 & 74 & 279 & 157 & 65 \\
Meconopsis cambrica orange & 5 & 73 & 289 & 142 & 29 \\
Argemone polyanthemos & 3 & 131 & 407 & 266 & 89 \\
\hline
\end{tabular}

Per petal, thicknesses were measured five times on a transect from proximal to distal (see "Materials and methods") 
line with observations by Kay et al. (1981), our anatomical investigations showed that the petals consist of three main layers, i.e., a pigmented upper and lower epidermis, with an unpigmented (mesophyll) layer in between. We hence deployed the optical model that we developed for understanding the colours of the Chilean bellflower, Nolana paradoxa, which combines the Kubelka-Munk theory for absorbing and scattering media with a layer-stack light-propagation model (Stavenga and van der Kooi 2016). Using measured transmittance spectra as well as adaxial and abaxial reflectance spectra, we could calculate the absorbance parameter $K^{*}=K d$ and scattering parameter $S^{*}=S d$, where $K$ and $S$ are the absorption and scattering coefficients and $d$ the petal thickness. The modelling showed that asymmetric petals consisting of one pigmented and one unpigmented layer cause very different adaxial and abaxial colours. However, identical adaxial and abaxial reflectance spectra result when the petal is homogeneously pigmented or symmetrically organized into three layers, and the pigment is equally distributed in the two peripheral layers. Using the calculated absorption and scattering parameters in a calculation of the transmittance and reflectance spectra for a symmetrical, three-layer case yielded spectra virtually identical to the experimentally measured spectra. Finally, the transmittance of a homogeneously pigmented layer with absorption coefficient $K$ and thickness $d$ is calculated as:

$T=\exp \left(-K^{*}\right)$,

so that the absorbance is

$D=-\log _{10}(T)=g K^{*}=K^{\prime}$,

with $g=\log 10(e)=0.4343$.

\section{Vision modelling}

We investigated the visibility of the flowers with a pollinator-subjective view for known poppy pollinators, i.e., honey bees. We analysed the measured reflectance spectra under D65 ambient light against a green leaf background as before (van der Kooi et al. 2016), with two well-established vision models, i.e., the color hexagon model (Chittka 1992) and the receptor noise-limited model (Vorobyev and Osorio 1998). Both models yield values that correlate with the flower contrast as perceived by bees. Green contrast was calculated as per Spaethe et al. (2001).

\section{Results}

\section{Poppies vary in coloration and pigmentation}

The common poppy (P. rhoeas) features typically red flowers, with at the petal base often a distinctly black area bordered by a thin white line (Fig. 1a). The reflectance and transmittance values at very long wavelengths $(>900 \mathrm{~nm})$ can be used to quantify the backscattering by the petal, because in that wavelength range absorption by pigments is negligible (see also van der Kooi et al. 2016). For both the distal and proximal areas, the transmittance is $\sim 0.65$ and the reflectance $\sim 0.35$ (Fig. 1), meaning that the petals scatter approximately $35 \%$ of incident light. Even in the case of the proximal (base) area, which is deeply black coloured, the reflectance and transmittance curves plateau at similar amplitude in the long wavelength range. Although the longwavelength reflectance of $\sim 0.35$ may seem to be in conflict with the blackness of the base area, the reflectance in the visible wavelength range is small and the gradual increase in reflectance at wavelengths $>600 \mathrm{~nm}$ is too small to give a colourful signal. The low transmittance and reflectance at shorter wavelengths must be due to strongly light-absorbing pigments. The different slopes of the distal and proximal spectra at wavelengths $>550 \mathrm{~nm}$ indicate different pigments. In the ultraviolet wavelength range, the transmittance and reflectance of the distal area is distinctly higher than the corresponding value for the proximal part, which also indicates the presence of a different pigment.

The long-headed poppy ( $P$. dubium) displays similarly beautiful red flowers, although this species rarely has black basal areas (Fig. 1d). The spectral slopes of the distal and proximal spectra in the long wavelength range are somewhat similar, but the spectral values in the ultraviolet measured at the proximal area are clearly lower than those for the distal area, indicating different amounts of ultraviolet-absorbing pigment (Fig. 1e,f). The Welsh poppy (M. cambrica) has an orange (Fig. 2a) and a yellow morph (Fig. 2b), and their transmittance and reflectance spectra are similar for all petal areas (Fig. 2c, d). The valleys in the spectra indicate the presence of a pigment absorbing mainly in the blue wavelength range. The crested prickly poppy (A. polyanthemos) has white flowers that are somewhat larger than for other species. The valley in the spectra of $A$. polyanthemos indicate a pigment absorbing exclusively in the ultraviolet wavelength range. For A. polyanthemos, there were no differences in reflectance between different flower areas.

Ultraviolet photography showed that there are no great differences in coloration of the petals, but the flowers as a whole feature a contrasting ultraviolet pattern. Flower patterns with ultraviolet-absorbing centres and ultravioletreflecting peripheries are known as "bulls-eye patterns", due to the absence of ultraviolet reflection of the anthers and stigma (Fig. S1).

\section{Pigmentation and scattering is localised}

The transmittance and reflectance spectra of flowers depend on both the absorption of incident light by pigments and the 
Fig. 1 Habitus pictures and spectra of two exemplary poppies. a-c $P$. rhoeas. $\mathbf{d}-\mathbf{f} P$. dubium. Transmittance $(T)$ and adaxial $\left(R_{\mathrm{ad}}\right)$ and abaxial $\left(R_{\mathrm{ab}}\right)$ reflectance spectra of distal $(\mathbf{b}-\mathbf{e})$ and proximal $(\mathbf{c}-\mathbf{f})$ petal areas. Scale bars $(\mathbf{a}, \mathbf{b}) 1 \mathrm{~cm}$
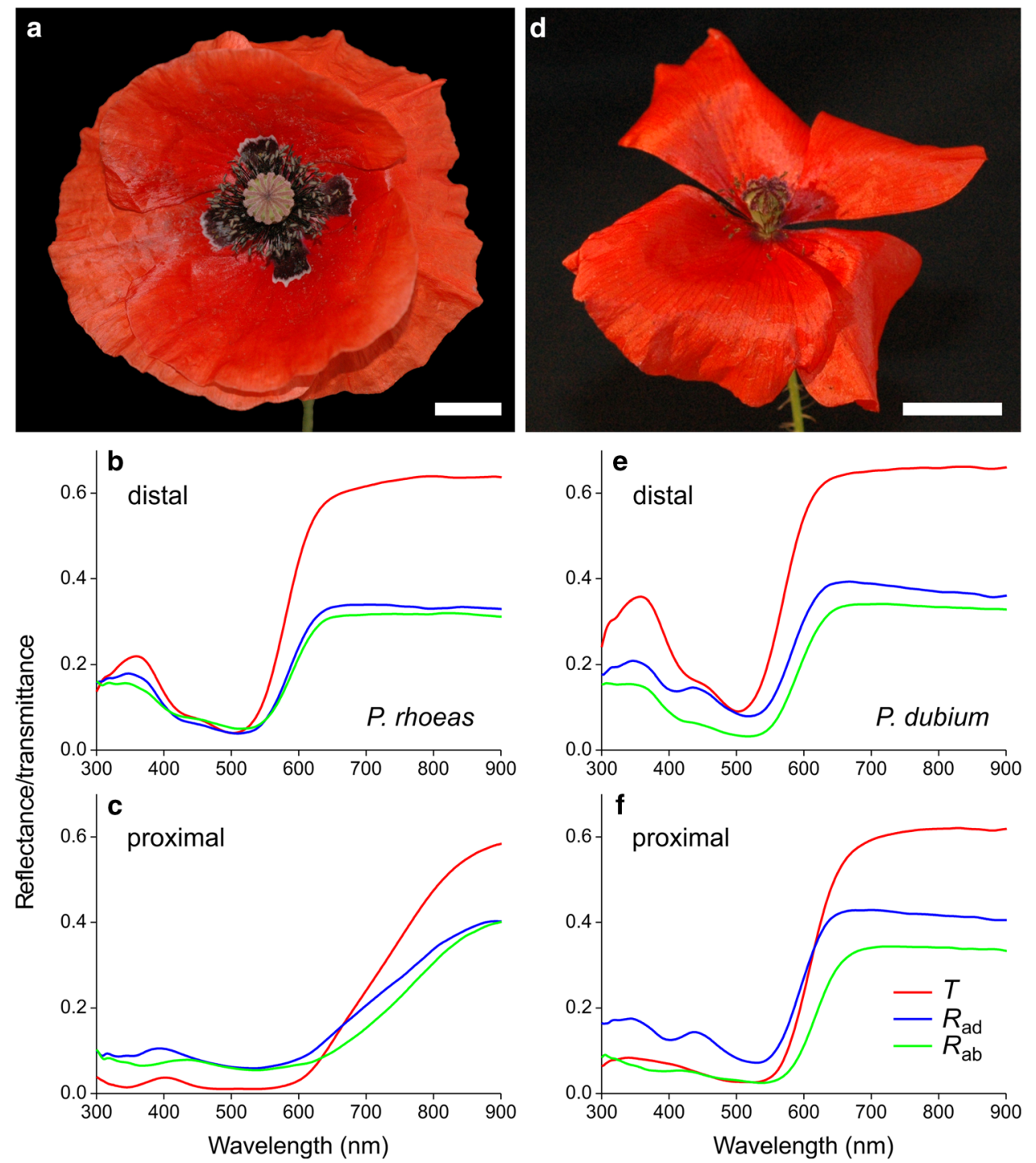

scattering by the floral structures. We observed the petals at high magnification with our Zeiss microscope ("Materials and methods"), applying epi-illumination as well as transmitted light (Fig. 3). With epi-illumination, the faint linear surface reflections observed at the proximal part of a P. rhoeas petal reveal very elongated, convex cells (Fig. 3c). In line with reflectance spectra obtained for this black area (Fig. 1a, c), the images showed that backscattering in the visible wavelength range by the components inside the proximal cells is low (Fig. 3a). In transmitted light, the cells nevertheless appear purplish (Fig. 3b), corresponding to the non-negligible transmittance in the violet and red wavelength range (Fig. 1c).

The appearance of the distal petal areas is different. Epiillumination also creates an assembly of faint, linear surface reflections, but the reflections from inside the petal are bright-red (Fig. 3c). In transmitted light, the cells are also red, but at locations complementary to those appearing with epi-illumination (Fig. 3d). The elongated epidermal cells seem to be compartmentalised (Fig. 3c, d), but the compartmentalisation is an optical illusion caused by the wavy cell walls. The petal's wavy cell walls are more clearly observed in oil immersion: epi-illumination reveals serpentine-wavy cell boundaries that appear bright, whereas in transmitted light mostly the cell interior is brightest (Fig. 3e, f).

The flowers of M. cambrica feature a similar complementary behaviour of reflection and transmission (Fig. 4a, b). For yellow M. cambrica flowers, transverse sections furthermore revealed that the short-wavelength absorbing, yellow transmittant pigment is located in only the upper and lower epidermal cells, whereas the mesophyll layer in between is unpigmented (Fig. 4c). A similar epidermal deposition of pigment has been described for $P$. rhoeas (Kay et al. 1981) and $M$. grandis (Yoshida et al. 2006), and is typical for anthocyanins (Kay et al. 1981; Lee 2007). 

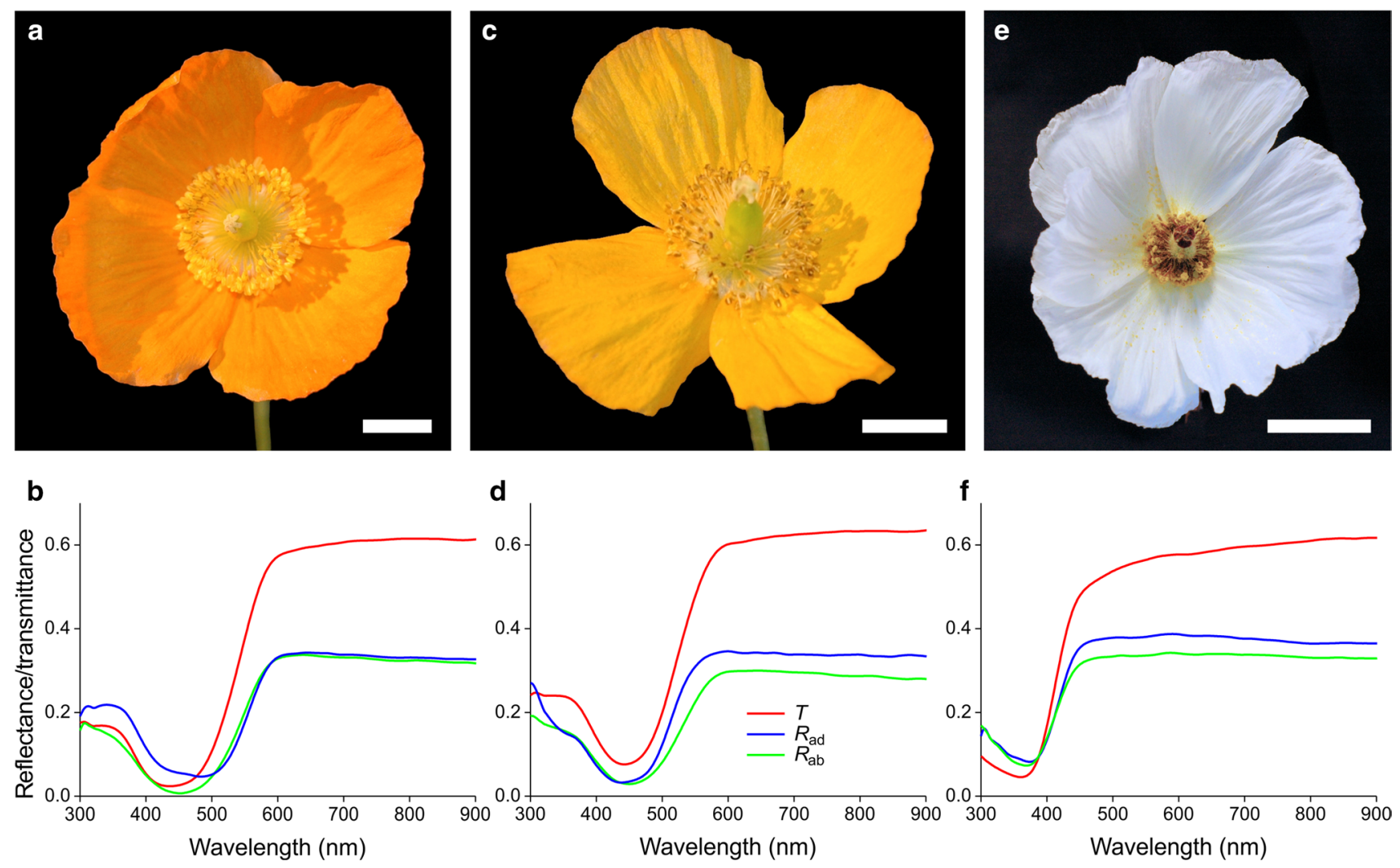

Fig. 2 Flowers and spectral characteristics of the studied species. a, c Yellow and orange type Meconopsis cambrica. e Argemone polyanthemos. b, d, f Transmittance $(T)$ and adaxial $\left(R_{\mathrm{ad}}\right)$ and abaxial $\left(R_{\mathrm{ab}}\right)$

The bright cell boundaries observed in epi-illumination versus the bright cell interior under transmitted light suggest the presence of scattering structures around and/or in between the (epidermal) cells. We investigated the presence of air cavities further by cutting a petal of a common poppy ( $P$. rhoeas), about perpendicularly to the axes of the epidermal cells, and exposing the cut surface to water. Initially, the images were turbid (not shown), but starting from the cut surface the image clarified, and after a few minutes a clear image of the flower area resulted (Fig. 5). Figure $\mathrm{S} 2$ shows the same flower area at three different planes of focus: the upper epidermis, the interior, mesophyll layer, and the lower epidermis layer (Fig. S2a-c, respectively). The turbid area (Figs. 5, S2a-c, top) represents an area with strongly scattering air cavities, and thus appears dark under transmission. The elongated, homogeneous red coloured cells (Figs. 5, S2a-c, middle area) have become clearly visible, because the air cavities were filled with water by capillary action. The transected epidermal cells became transparent, due to leakage of the red colouring pigment (Figs. 5 double-headed arrow, S2a-c bottom). reflectance spectra b yellow $M$. cambrica; $\mathbf{d}$ orange $M$. cambrica; $\mathbf{f} A$. polyanthemos. Scale bar a, c, $1 \mathrm{~cm} ; \mathbf{e} 2 \mathrm{~cm}$

\section{Pigments absorb exclusively in the ultraviolet or well into the red wavelength range}

To obtain a closer view of the absorption properties of the various poppy pigments, we calculated the absorbance of the flowers shown in Fig. 1 (see "Materials and methods"). The absorbance spectra indicate that the distal areas of $P$. rhoeas and $P$. dubium petals contain the same pigment, with a lower density in P. dubium (Fig. 6a). The pigment in the proximal area of $P$. rhoeas is different, however, as it has a much higher absorbance tail in the red as well as an ultraviolet peak. The absorbance spectra of the orange and yellow M. cambrica are proportional, meaning that the two morphs feature the same pigment, but the amount is much higher in the orange morph. Finally, the absorbance spectrum of $A$. polyanthemos is almost fully restricted to the ultraviolet, which is typical for flowers that appear white to the human eye (Chittka et al. 1994; Kevan et al. 1996; van der Kooi et al. 2016).

The absorbance spectra of Fig. 6 represent only an approximation of the absorption properties of the various 

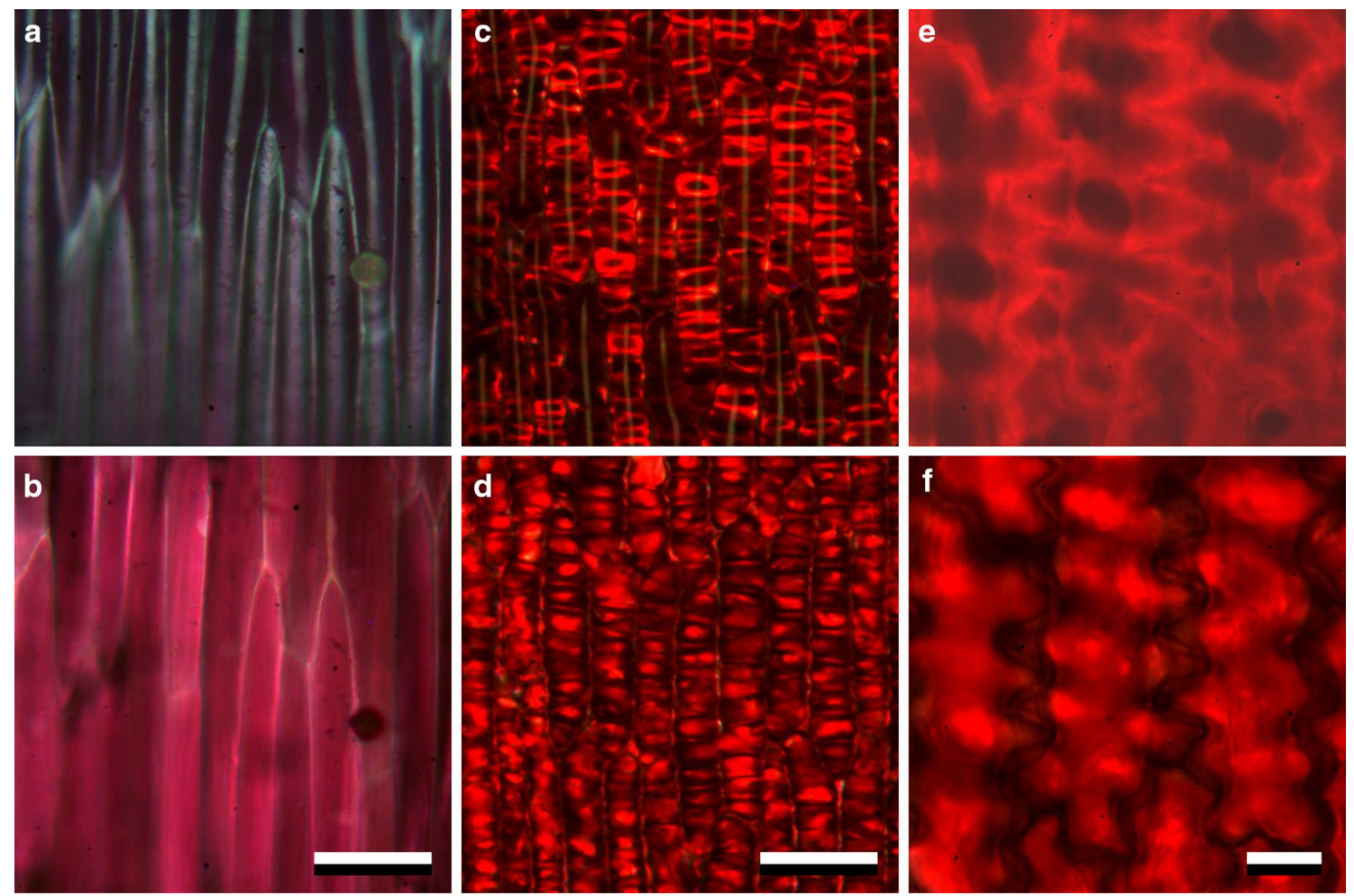

Fig. 3 P. rhoeas petal areas observed close up (all top view). a, b Proximal area. $\mathbf{c}-\mathbf{f}$ Distal areas. $\mathbf{a}-\mathbf{d}$ Petal pieces in air. e, $\mathbf{f}$ Petal piece immersed in oil. Top row, a, c, e images observed with epi-illumi-

poppy pigments, because the different species of flower will have different scattering properties, especially given their markedly different thicknesses (Table 1). We previously developed an optical model that considers a flower as a stack of absorbing and scattering media, which we successfully applied to study the optics of the Chilean bellflower, buttercups and other flowers (Stavenga and van der Kooi 2016; van der Kooi et al. 2016, 2017). We applied the same model to $P$. rhoeas flowers and thus obtained the spectra of the absorption and scattering parameters for the distal and proximal petal parts (Fig. 7). The scattering parameters are clearly wavelength dependent, which is related to the absorption by the pigment. When we compare the experimental absorbance spectra with the modelled absorbance spectra, it appears that scattering has only a minor effect (for calculation procedures, see "Materials and methods").

\section{Obliquely incident light causes polarised reflections}

The reflectance spectra shown in Figs. 1 and 2 were measured for normal illumination, when surface reflection is generally very small (van der Kooi et al. 2014, 2015). Under large angles, however, surface reflection will increase, and when reflected by a smooth surface it becomes polarised (Wehner 2001). Indeed, under large angles relative to the nation. Bottom row, $\mathbf{b}, \mathbf{d}, \mathbf{f}$ images observed with transmitted light. Scale bars a-d $50 \mu \mathrm{m} ; \mathbf{e}, \mathbf{f} 10 \mu \mathrm{m}$

normal, there are clear differences in reflectance amplitude between horizontally and linearly polarised light (Fig. 8a, b). In the blue and green wavelength ranges, the polarisation response of the petal was very similar to that of a water surface, with a Brewster angle at $\sim 55^{\circ}$ (Fig. 8c). For ultraviolet wavelengths, this was less distinct, but nevertheless oblique incident light causes significant polarisation.

\section{Discussion}

Our study on the optical properties of poppy flowers revealed that they feature an interesting suite of optical and anatomical traits. Papaver flowers are exceedingly thin (Table 1), but contain a high amount of pigment and are fairly strong reflectors. Indeed, the (long-wavelength) reflectance value of $35 \%$ is high when considering their very minimal thickness (van der Kooi et al. 2016).

How can poppy flowers, with their average thickness of only three cell layers, be such efficient reflectors? The answer comes with the interior structure and shape of their cell walls. Microscopical investigation of individual cells showed that the serpentine-curved epidermal cell walls in combination with surrounding structures strongly scatter the light flux propagating in the petal interior, thus causing 

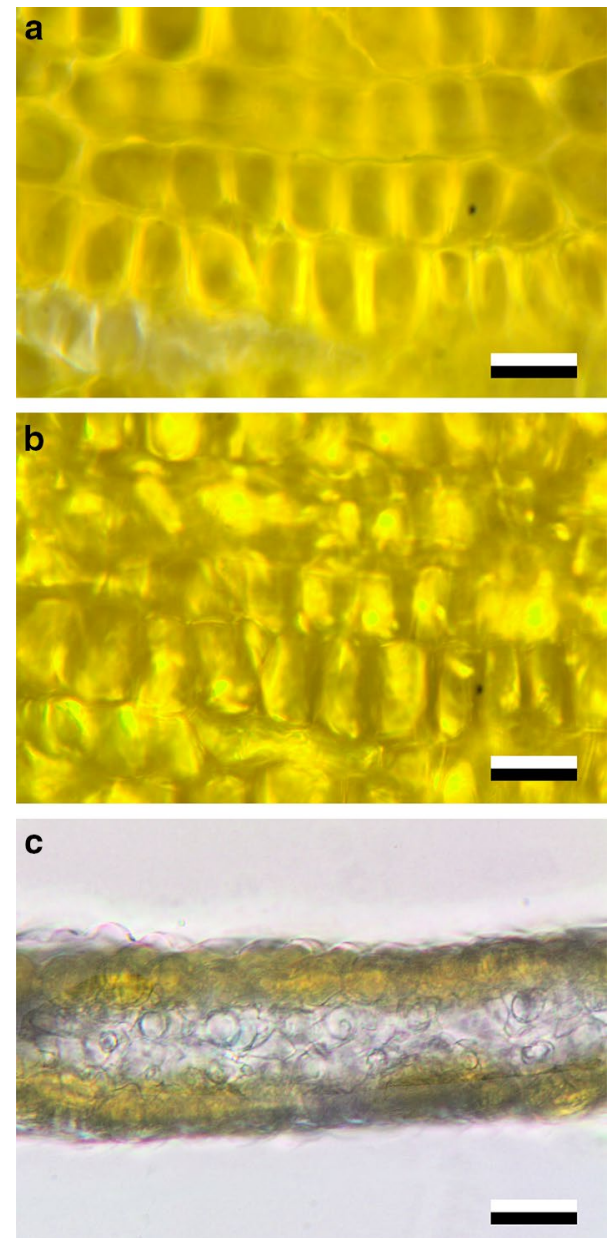

Fig. 4 Structure of yellow Meconopsis cambrica flowers. a Close-up of epi-illuminated petal (top view). b The same area as in a transilluminated (top view). c Cross-section of the petal. Scale bars a, b $20 \mu \mathrm{m} ; \mathbf{c} 50 \mu \mathrm{m}$

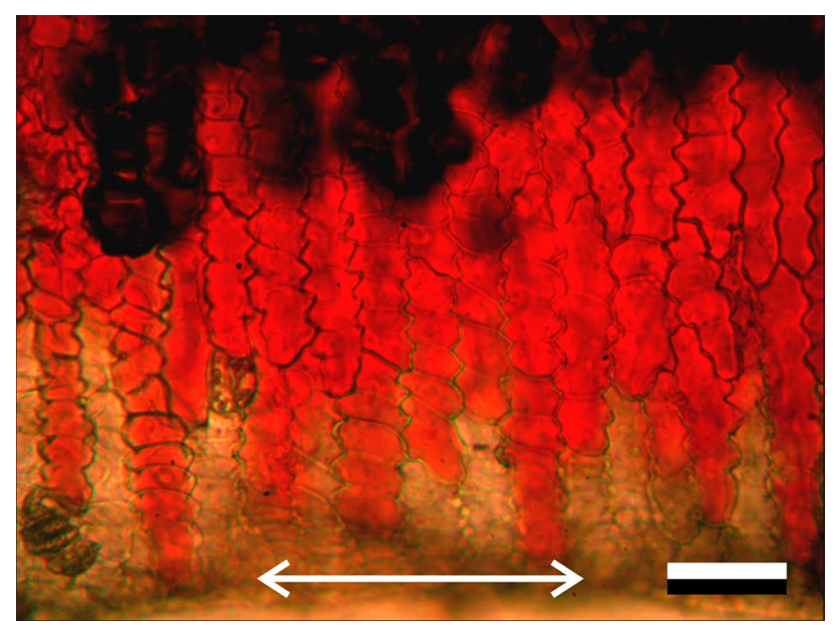

Fig. 5 A cut $P$. rhoeas petal immersed in water with focus at the upper epidermis level in transmission. The cut area, where the pigment is gone, is indicated by the double-headed arrow; in the top part the air holes are still intact, causing the blackness. Scale bar $50 \mu \mathrm{m}$
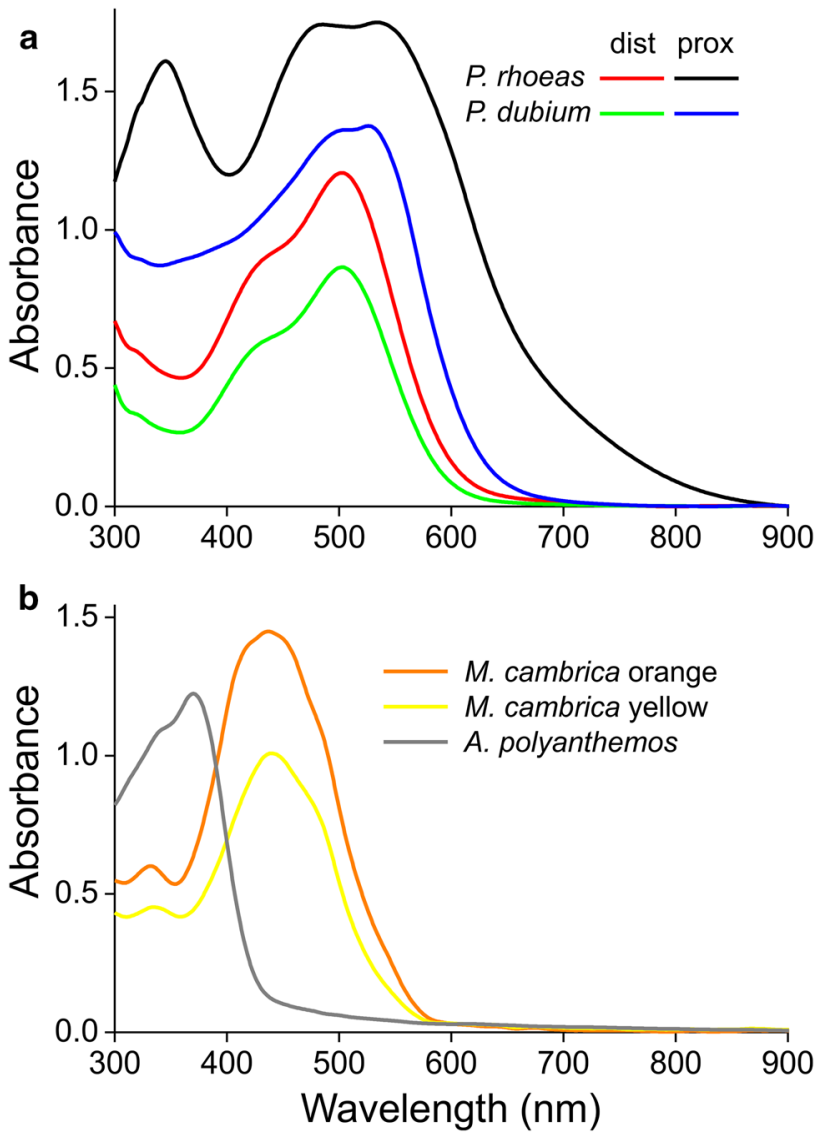

Fig. 6 Absorbance of poppy petals. a Absorbance spectra of distal and proximal areas of $P$. rhoeas and $P$. dubium petals. b Absorbance spectra of petals of orange and yellow type $M$. cambrica and of $A$. polyanthemos petals

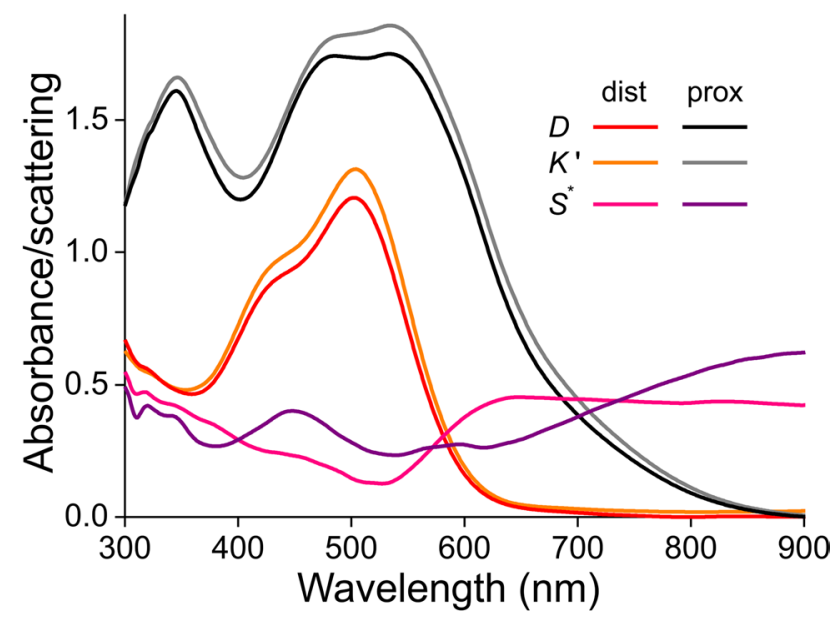

Fig. 7 Absorbance and scattering in a $P$. rhoeas flower. The absorbance $D$ of the distal (dist) and proximal (prox) part of the petal is identical to that of Fig. 6 a. The parameter $K^{\prime}=0.4343 K^{*}$, where $K^{*}$ is the absorption parameter that follows together with the scattering parameter $S^{*}$ from the Kubelka-Munk layer-stack model analysis 

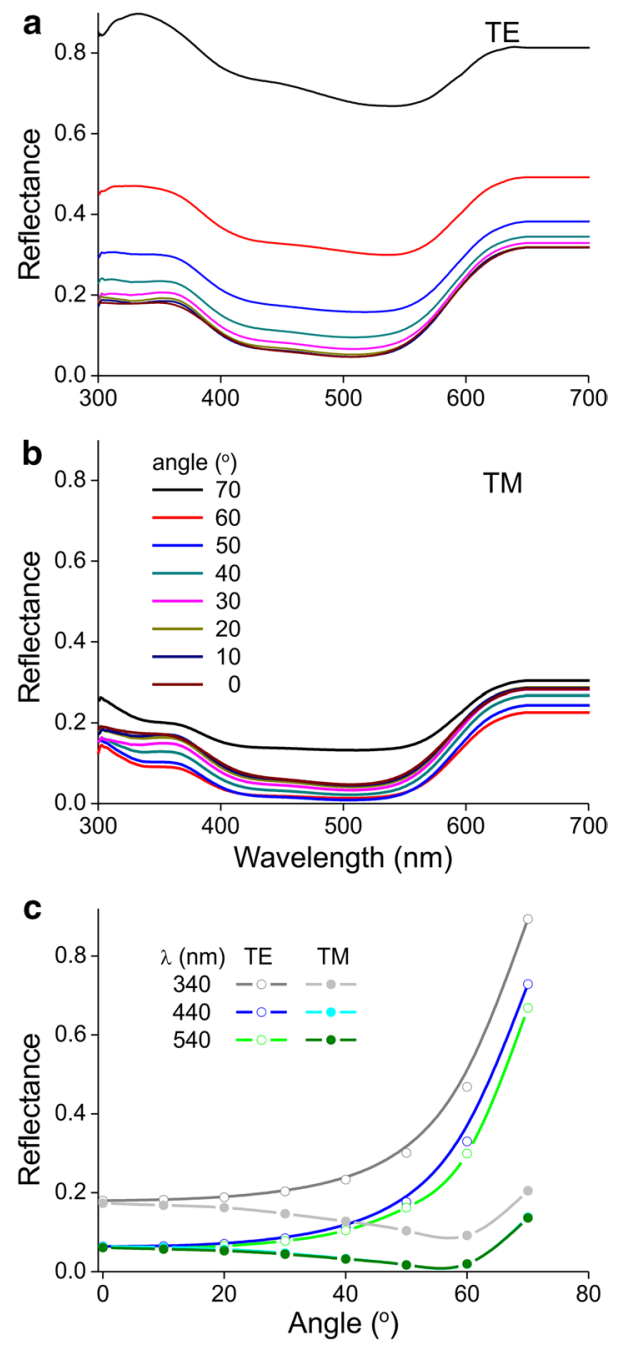

Fig. 8 Angle-dependent reflectance of a $P$. rhoeas flower. a Reflectance spectra for TE-polarised light incident at angles $0,10, \ldots 70^{\circ}$. b Reflectance spectra for TE-polarised light. c Reflectance values at wavelengths 340,440 and $540 \mathrm{~nm}$ - which correspond to the peak sensitivities of the honey bee's photoreceptors (Peitsch et al. 1992) as a function of angle of light incidence

the bright appearance in epi-illumination and being dark in transmitted light (Figs. 3, 4). In addition, the interior air cavities are very prominent scatterers, because of the great difference in refractive index between the plant material and air. Immersion of a cut petal shows that the air cavities are gradually filled with water via capillary suction, thereby reducing the reflection (Fig. 5). Similar within-flower air cavities have previously been demonstrated to exist in flowers of Caltha palustris (Whatley 1984) and California poppy (Wilts et al. 2018), and have been shown to enhance the brilliance of buttercup flowers (Vignolini et al. 2012; van der Kooi et al. 2017).

Intriguingly, scattering does not increase with petal thickness, suggesting that the strong scattering structures only occur just below the epidermal cell layers in Papaver flowers. The mean thickness of flowers of $M$. cambrica and $A$. polyanthemos is significantly higher than the mean thickness of P. rhoeas and P. dubium (Table 1), but the longwavelength reflectance values are similar (compare $R_{\mathrm{ad}}$ in Figs. 1,2). An interesting open question remains as to how widespread the highly reflective typical cell structure is. The curvy cell walls occur in Papaver and Meconopsis, which are closely related (Kadereit et al. 2011; Xie et al. 2014), but we also observed similar cell shapes in the phylogenetically more diverged A. polyanthemos and Chelidonium majus (not shown). Hence, the typical cell shape-perhaps in thin petals in conjunction with the strongly scattering air cavities-may be widespread throughout Papaveraceae. Given the curvy cell walls also occur in leaves of many angiosperms (Vőfély et al. 2018), they are likely to occur widely in flowers too.

The studied poppy species feature a wide array of colours, due to various floral pigments, with absorption maxima for different species peaking over the whole visible wavelength range (Fig. 6). Furthermore, the proximal and distal parts of $P$. rhoeas and $P$. dubium flowers contain different pigments. The red, orange and yellow flower colours are likely due to anthocyanin pigments (Grotewold 2006; Ng and Smith 2016), though chemical investigations are required to determine the exact type of pigment. Our observations that the pigments are water-soluble and occur only in the epidermal cell layers (Figs. 4, 5) indeed suggest the presence of anthocyanin pigments. Flower colour polymorphisms, as seen in M. cambrica, also most commonly occur with anthocyaninbased colours (Narbona et al. 2018).

For flowers of $P$. rhoeas, there appears to be an ultraviolet colour polymorphism linked to the visual system of their pollinators. In Europe, flowers of $P$. rhoeas reflect ultraviolet light (Daumer 1958; Lunau 1993; van der Kooi et al. 2016; this study) and are pollinated by bees (McNaughton and Harper 1960; Proctor et al. 1997), but in Israel, the flowers lack ultraviolet reflection and are pollinated by beetles (Dafni et al. 1990). Given that bees exhibit little sensitivity in the red part of the spectrum and high sensitivity in the ultraviolet (e.g., Peitsch et al. 1992), and some important flower-visiting Mediterranean beetle species are sensitive in the red part of the spectrum (e.g., Martínez-Harms et al. 2012), the lack of ultraviolet reflection in the eastern Mediterranean seems to be a convergence for beetle pollination (Dafni et al. 1990). The chemical characteristics of the floral pigments in different geographic regions will shed light on how ultraviolet-absorbing pigments were lost when $P$. rhoeas expanded its geographic range to Europe.

In contrast to the natural variability in ultraviolet reflection, there is no significant variation in red coloration of the two Papaver species, suggesting that the red coloration is more developmentally constrained and/or it serves a relevant signalling function for bees also. Indeed, although bees are 
Table 2 Vision modelling results

\begin{tabular}{lllc}
\hline Species & Green contrast & Hexagon units & RNL units \\
\hline P. rhoeas & 0.04 & 0.23 & 7.3 \\
P. dubium & 0.01 & 0.23 & 6.8 \\
M. cambrica yellow & 0.21 & 0.18 & 7.3 \\
M. cambrica orange & 0.16 & 0.30 & 11.6 \\
A. polyanthemos & 0.33 & 0.21 & 9.7 \\
\hline
\end{tabular}

Stimuli were compared against an average green backdrop, with D65 illuminant and spectral sensitivities for honey bees (see "Materials and methods")

commonly thought to be insensitive to red colours, Chittka and Waser (1997) have shown that this is not the case. The spectral sensitivity of bees extends until at least $650 \mathrm{~nm}$, and red poppy flowers feature noticeable reflection below that wavelength (Fig. 1). Interpretation of the colours with a bee subjective view showed that the red petals are strongly contrasting to a green background (Table 2). On the other hand, the green contrast, which is a (long-distance) visual signal used by some insect pollinators including bees (Giurfa et al. 1996; Spaethe et al. 2001; Hempel de Ibarra et al. 2014; van der Kooi et al. 2019), is very low for $P$. rhoeas and $P$. dubium (Table 2). Nonetheless, the fairly large floral display, the high colour contrast and the within-flower contrast in $P$. rhoeas and $P$. dubium may yield a visually strong signal. Furthermore, on a clear day and under oblique illumination, the surface reflection may enhance the (long-distance) visibility. Bees and other flower visitors may perceive the specular reflection as a flash, though it seems unlikely that any polarisation effect per se (Fig. 8) acts as a cue; for example, because the part of the bee eye that generally faces the flower is not polarisation-sensitive (for further discussion on polarised signalling by plants, see Wehner and Bernard 1993; van der Kooi et al. 2019).

The differently coloured anthers, the dark red in the proximal part of the petal and-if present - the black markings furthermore create a within-flower colour contrast, making the centre of the flower where the pollen are located to visually stand out (Figs. 1, 2, S1). In addition to generating within-flower contrast, the black markings may increase attractiveness to pollinators by means of sexual deception. Experiments with artificial $P$. rhoeas "flowers" and pollinators in natural Israeli habitats showed that visitation by male beetles increases with black markings, presumably because males are looking for female beetles that often dwell in these flowers (Dafni et al. 1990). Similar results have been reported for the fly-pollinated South African daisy, Gorteria diffusa (Johnson and Midgley 1997; Ellis et al. 2014).

In summary, our study shows that despite their minimal thickness and floppy appearance, poppy flowers exhibit an intriguing anatomy. High pigment content, wavy cell walls and interior air spaces, combined with black markings and anthers create a conspicuous flower.

Acknowledgements The authors thank Hein Leertouwer and Marten Staal for practical support, two reviewers for comments on the manuscript and Dr. Friedrich Barth for inviting us to contribute to this special issue. CJvdK was financially supported by a VENI Grant (Grant number 016.Veni.181.025, provided by the Dutch NWO) and DGS was financially supported by AFOSR/EOARD (Grant FA9550-15-1-0068).

OpenAccess This article is distributed under the terms of the Creative Commons Attribution 4.0 International License (http://creativeco mmons.org/licenses/by/4.0/), which permits unrestricted use, distribution, and reproduction in any medium, provided you give appropriate credit to the original author(s) and the source, provide a link to the Creative Commons license, and indicate if changes were made.

\section{References}

Barth FG (1991) Insects and flowers. The biology of a partnership. Princeton University Press, Princeton

Chittka L (1992) The colour hexagon: a chromaticity diagram based on photoreceptor excitations as a generalized representation of colour opponency. J Comp Physiol A 170:533-543

Chittka L, Menzel R (1992) The evolutionary adaptation of flower colours and the insect pollinators' colour vision. J Comp Physiol A 171:171-181

Chittka L, Waser NM (1997) Why red flowers are not invisible to bees. Isr J Plant Sci. https://doi.org/10.1080/07929978.1997.10676682

Chittka L, Shmida A, Troje N, Menzel R (1994) Ultraviolet as a component of flower reflections, and the colour perception of Hymenoptera. Vis Res 34:1489-1508

Dafni A, Bernhardt P, Shmida A et al (1990) Red bowl-shaped flowers: convergence for beetle pollination in the Mediterranean region. Isr J Bot 39:81-92. https://doi.org/10.1080/0021213X.1990.10677 134

Daumer K (1958) Blumenfarben, wie sie die Bienen sehen. Z Vergl Physiol 41:49-110

Dyer AG, Boyd-Gerny S, McLoughlin S et al (2012) Parallel evolution of angiosperm colour signals: common evolutionary pressures linked to hymenopteran vision. Proc R Soc B 279:3606-3615. https://doi.org/10.1098/rspb.2012.0827

Ellis AG, Brockington SF, de Jager ML et al (2014) Floral trait variation and integration as a function of sexual deception in Gorteria diffusa. Philos Trans R Soc Lond B Biol Sci 369:20130563. https ://doi.org/10.1098/rstb.2013.0563

Giurfa M, Vorobyev M, Kevan P, Menzel R (1996) Detection of coloured stimuli by honeybees: minimum visual angles and receptor specific contrasts. J Comp Physiol A 178:699-709

Grotewold E (2006) The genetics and biochemistry of floral pigments. Annu Rev Plant Biol 57:761-780. https://doi.org/10.1146/annur ev.plant.57.032905.105248

Hempel de Ibarra N, Vorobyev M, Menzel R (2014) Mechanisms, functions and ecology of colour vision in the honeybee. J Comp Physiol A 200:411-433

Hopkins R, Rausher MD (2011) Identification of two genes causing reinforcement in the Texas wildflower Phlox drummondii. Nature 469:411-414

Johnson SD, Midgley JJ (1997) Fly pollination of Gorteria diffusa (Asteraceae), and a possible mimetic function for dark spots on the capitulum. Am J Bot 84:429-436. https://doi.org/10.2307/24460 18 
Kadereit JW, Preston CD, Valtueña FJ (2011) Is Welsh Poppy, Meconopsis cambrica (L.) Vig. (Papaveraceae), truly a Meconopsis? New J Bot 1:80-88. https://doi.org/10.1179/204234811X13194 453002742

Kay QON, Daoud HS, Stirton CH (1981) Pigment distribution, light reflection and cell structure in petals. Bot J Linn Soc 83:57-83. https://doi.org/10.1111/j.1095-8339.1981.tb00129.x

Kevan PG, Backhaus WGK (1998) Color vision: ecology and evolution in making the best of the photic environment. In: Backhaus WGK, Kliegl R, Werner JS (eds) Color vision: perspectives from different disciplines. De Gruyter, Berlin

Kevan P, Giurfa M, Chittka L (1996) Why are there so many and so few white flowers? Trends Plant Sci 1:252-527

Koes RE, Quattrocchio F, Mol JNM (1994) The flavonoid biosynthetic pathway in plants: function and evolution. BioEssays 16:123-132

Lee DW (2007) Nature's Palette. The science of plant color. University of Chicago Press, Chicago

Lunau K (1993) Interspecific diversity and uniformity of flower colour patterns as cues for learned discrimination and innate detection of flowers. Experientia 49:1002-1010

Martínez-Harms J, Vorobyev M, Schorn J et al (2012) Evidence of red sensitive photoreceptors in Pygopleurus israelitus (Glaphyridae: Coleoptera) and its implications for beetle pollination in the southeast Mediterranean. J Comp Physiol A 198:451-463. https://doi. org/10.1007/s00359-012-0722-5

McNaughton IH, Harper JL (1960) The comparative biology of closely related species living in the same area. I External breeding-barriers between Papaver species. New Phytol 59:15-26. https://doi. org/10.1111/j.1469-8137.1960.tb06197.x

Mol J, Grotewold E, Koes R (1998) How genes paint flowers and seeds. Trends Plant Sci 3:212-217

Muchhala N, Johnsen S, Smith SD (2014) Competition for hummingbird pollination shapes flower color variation in Andean Solanaceae. Evolution 68:2275-2286. https://doi.org/10.1111/ evo. 12441

Narbona E, Wang H, Ortiz PL et al (2018) Flower colour polymorphism in the Mediterranean Basin: occurrence, maintenance and implications for speciation. Plant Biol 20:8-20

$\mathrm{Ng}$ J, Smith SD (2016) How to make a red flower: the combinatorial effect of pigments. AoB Plants 8:plw013. https://doi.org/10.1093/ aobpla/plw013

Peitsch D, Fietz A, Hertel H et al (1992) The spectral input systems of hymenopteran insects and their receptor-based color-vision. J Comp Physiol A 170:23-40

Proctor M, Yeo P, Lack A (1997) The natural history of pollination. Harper Collins, New York

Raguso RA (2004) Flowers as sensory billboards: progress towards an integrated understanding of floral advertisement. Curr Opin Plant Biol 7:434-440

Rausher MD (2008) Evolutionary transitions in floral color. Int J Plant Sci 169:7-21

Sheehan H, Moser M, Klahre U et al (2016) MYB-FL controls gain and loss of floral UV absorbance, a key trait affecting pollinator preference and reproductive isolation. Nat Genet 48:159

Shrestha M, Lunau K, Dorin A et al (2016) Floral colours in a world without birds and bees: the plants of Macquarie Island. Plant Biol 18:842-850. https://doi.org/10.1111/plb.12456

Spaethe J, Tautz J, Chittka L (2001) Visual constraints in foraging bumblebees: flower size and color affect search time and flight behavior. Proc Natl Acad Sci USA 98:3898-3903

Stavenga DG, van der Kooi CJ (2016) Coloration of the Chilean Bellflower, Nolana paradoxa, interpreted with a scattering and absorbing layer stack model. Planta 243:171-181. https://doi. org/10.1007/s00425-015-2395-0

Strain HH (1938) Eschscholtzxanthin: a new xanthophyll from the petals of the California poppy, Eschscholtzia californica. J Biol Chem 123:425-437

van der Kooi CJ, Wilts BD, Leertouwer HL et al (2014) Iridescent flowers? Contribution of surface structures to optical signaling. New Phytol 203:667-673. https://doi.org/10.1111/nph.12808

van der Kooi CJ, Dyer AG, Stavenga DG (2015) Is floral iridescence a biologically relevant cue in plant-pollinator signaling? New Phytol 205:18-20. https://doi.org/10.1111/nph.13066

van der Kooi CJ, Elzenga JTM, Staal M, Stavenga DG (2016) How to colour a flower: on the optical principles of flower coloration. Proc R Soc B 283:20160429. https://doi.org/10.1098/rspb.2016.0429

van der Kooi CJ, Elzenga JTM, Dijksterhuis J, Stavenga DG (2017) Functional optics of glossy buttercup flowers. J R Soc Interface 17:20160933. https://doi.org/10.1098/rsif.2016.0933

van der Kooi CJ, Dyer AG, Kevan PG, Lunau K (2019) Functional significance of the optical properties of flowers for visual signalling. Ann Bot 123:263-276. https://doi.org/10.1093/aob/mcy119

Vignolini S, Thomas MM, Kolle M et al (2012) Directional scattering from the glossy flower of Ranunculus: how the buttercup lights up your chin. J R Soc Interface 9:1295-1301. https://doi.org/10.1098/ rsif.2011.0759

Vófély RV, Gallagher J, Pisano GD et al (2018) Of puzzles and pavements: a quantitative exploration of leaf epidermal cell shape. New Phytol 221:540-552. https://doi.org/10.1111/nph.15461

Vorobyev M, Osorio D (1998) Receptor noise as a determinant of colour thresholds. Proc R Soc Lond B 265:351-358

Vukusic P, Stavenga DG (2009) Physical methods for investigating structural colours in biological systems. J R Soc Interface 6:S133S148. https://doi.org/10.1098/rsif.2008.0386.focus

Wehner R (2001) Polarization vision-a uniform sensory capacity? J Exp Biol 204:2589-2596. https://doi.org/10.1016/00426989(77)90005-0

Wehner R, Bernard GD (1993) Photoreceptor twist: a solution to the false-color problem. Proc Natl Acad Sci USA 90:4132-4135

Whatley JM (1984) The ultrastructure of plastids in the petals of Caltha palustris L.. New Phytol 97:227-231. https://doi. org/10.1111/j.1469-8137.1984.tb04126.x

Wilts BD, Rudall PJ, Moyroud E et al (2018) Ultrastructure and optics of the prism-like petal epidermal cells of Eschscholzia californica (California poppy). New Phytol 219:1124-1133. https://doi. org/10.1111/nph.15229

Xie H, Ash JE, Linde CC et al (2014) Himalayan-Tibetan plateau uplift drives divergence of polyploid poppies: Meconopsis viguier (Papaveraceae). PLoS One 9:e99177. https://doi.org/10.1371/ journal.pone.0099177

Yoshida K, Kitahara S, Ito D, Kondo T (2006) Ferric ions involved in the flower color development of the Himalayan blue poppy, Meconopsis grandis. Phytochemistry 67:992-998. https://doi. org/10.1016/j.phytochem.2006.03.013

Zhao D, Tao J (2015) Recent advances on the development and regulation of flower color in ornamental plants. Front Plant Sci 6:261. https://doi.org/10.3389/fpls.2015.00261

Publisher's Note Springer Nature remains neutral with regard to jurisdictional claims in published maps and institutional affiliations. 